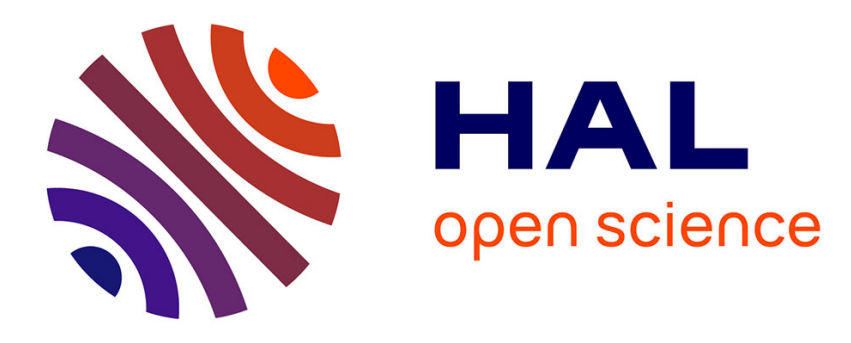

\title{
Industrial applications of ion track technology
}

H. Hanot, E. Ferain

\section{- To cite this version:}

H. Hanot, E. Ferain. Industrial applications of ion track technology. The Seventh International Symposium on Swift Heavy Ions in Matter, Jun 2008, Lyon, France. hal-00277232

\section{HAL Id: hal-00277232 \\ https://hal.science/hal-00277232}

Submitted on 30 May 2008

HAL is a multi-disciplinary open access archive for the deposit and dissemination of scientific research documents, whether they are published or not. The documents may come from teaching and research institutions in France or abroad, or from public or private research centers.
L'archive ouverte pluridisciplinaire HAL, est destinée au dépôt et à la diffusion de documents scientifiques de niveau recherche, publiés ou non, émanant des établissements d'enseignement et de recherche français ou étrangers, des laboratoires publics ou privés. 


\title{
Industrial applications of ion track technology
}

\author{
H. Hanot ${ }^{1}$, E. Ferain ${ }^{1,2}$ \\ ${ }^{1}$ it 4ip sa (ion track technology for innovative products) \\ Activalis (Z.I. C), rue Jules Bordet, 7180 Seneffe, Belgium \\ http:/www.it4ip.be - contact@it4ip.be \\ ${ }^{2}$ Unité de physique et de chimie des hauts polymères, Université catholique de Louvain \\ Croix du Sud, 1, 1348 Louvain-la-Neuve, Belgium
}

\begin{abstract}
it4ip s.a. is a spin out from the Universite catholique de Louvain (Belgium) dedicated to the development and production of unique templates and membranes based on the combination of ion track technology of polymers. It supplies customers with hi-tech products, state-of-the-art research and product development services with template capability to make high value added membranes.

Notably based on results coming from several collaborative $R \& D$ projects supported by European and Regional funding, recent improvements of ion track technology open new doors for fast growing applications in niche markets. This paper reviews some of these Hi-Tec applications in different fields such as in healthcare (oncology, drug control release combined to implant, artificial organs, ...), energy (fuel cells, batteries, ...), water de-contamination and electronics (OLED ...).
\end{abstract}




\section{Introduction}

A membrane is a thin porous film (polymeric, metal, paper, etc.) through which a fluid (liquid, gas) is filtered in order to carry out a separation. Types of filtration are subdivided according to the size of the particles or technology used. Microfiltration uses pores ranging from 0.1 to $10 \mu \mathrm{m}$ where membranes can be used to eliminate all of the bacteria. As viruses can bind to bacterial biofilm, viral contamination is also partially retained by this process although the viruses are much smaller than the pores of this type of membrane. Microfiltration is therefore used in many treatment processes where particles of a diameter larger than $0.1 \mu \mathrm{m}$ are eliminated. Ultrafiltration, reverse osmosis and nanofiltration are also considered for smaller particle sizes and nanofiltration has been developed more recently for water purification such as softening, dye removal and elimination of micro pollutants.

\section{Track etching technology}

Track etched membrane process was firstly patented by Price and Walker in General Electrics. It consists of a two-steps process involving a nuclear reactor and a etch bath. The resulting membranes were manufactured and marketed by Nuclepore Corporation early seventies.

The it4ip technology is used to perforate thin polymeric films : the film is first bombarded with energetic heavy ions accelerated for example in a cyclotron. The polymer chemical bonds are therefore damaged by these heavy ions leading to the creation of linear damaged tracks. In a second step, these tracks can be selectively chemically etched to produce "track-etched" membranes (Figure 1).

The basic technology is mainly used for the realization of microporous membranes from 10 to $20 \mu \mathrm{m}$ thick polycarbonate (PC) and polyethylene terephthalate (PET) films and with randomly distributed pores from 0.1 to $10 \mu \mathrm{m}$ in size. This technology, developed in the mid-1980s by Professor Legras and his team at the Université catholique de Louvain (Belgium), led to the creation of Cyclopore ${ }^{\circledR}$ track etched membranes. This research topic was further considered from the mid-1990s and track etching technology has therefore considerable progress to open up new opportunities in the field of nanotechnology.

New type of polymers are now track etchable and a better control of the pore geometry and of the pore size distribution can be reached (Figure 2). Moreover, these new membranes can be used as template for the controlled synthesis of metallic or polymeric nanowires or nanotubes; these nanoobjects (films, supported thin layers) or nanostructures have potentialities for a broad variety of high-technology applications in fast-growth nanotechnology markets.

Use of polyimide (PI) track etched membrane makes possible their optimal use up to $430{ }^{\circ} \mathrm{C}$ with an improvement of their chemical and physical resistance properties in comparison with PC and PET. Use of PI track-etched membrane is therefore foresees for ultra precise separation under extreme temperature conditions or chemical stress. Moreover, PI is also a well-known polymer in the field of electronics. 
Track etching technology can be also applied for the creation of regular porous networks in which porous areas are surrounded by nonporous zones (figure 3). This technology makes it possible to consider applications in the field of multipurpose sensors and multiple-well plates in which a high number of analyses can be carried out at reduced analysis costs and at reduced analyzer weight; for example, all blood analyses could be carried out in less time using only one drop of blood (space applications, combat situations, general public, and lab-on-a-chip).

\section{Applications}

\subsection{Bacteria detection}

High-technology membranes intended for the detection of microorganisms are used in the pharmaceutical, cosmetic, and food industries. Conventional microbiology is very slow and results cannot be expected before 1 to 14 days and implies inconsistent sensitivity as results vary with microbial populations, media and conditions. Also, spores, stressed and fastidious organisms require extended growth periods. In order to speed up release of sensitive and eventually very costly batch of production, very low fluorescent background track etched membranes have been developed. These membranes show very precise pore size, they are dyed, eventually metal coated and manufactured in ultra-clean conditions as single cell detection is the key feature of the technology.

In this simple 3 step application, samples of media (food, liquid, beverage...) are filtered through a low-fluorescence background precise nanofiltration membrane in order to collect bacteria on the smooth flat surface. These bacteria are then labeled and the membrane is analyzed under fluorescence microscope. This last step can eventually be automated with scanning equipment.

\subsection{Bio-sensors}

In the diagnostic field, the membrane is used as a control barrier in glucose sensors (Figure 4). The membrane has mainly 2 specific goals. Firstly, the precision of the nano pores size distribution allows very controlled flow of the element to be measured (for example glucose, lactate...) to the heart of the electrode and secondly, the sharp cut-off avoids any risk of contamination by cells, proteins or other elements present in the media.

\subsection{Artificial pancreas}

More than 80 million Europeans suffer from type 1 diabetes. This form of diabetes is characterized by insufficient insulin secretion, resulting in hypoglycemia. The condition is responsible for long-term complications such as coronary diseases, renal problems, and loss of 
vision. Transplantation of the pancreas is possible, but the number of donors is limited and problems arise due to the toxicity of the immunosuppressive drugs used, not to mention the risk of rejection.

The approach discussed here consists of encapsulating small islets of Langerhans in a porous biocompatible synthetic matrix (the implant), which stops the immunizing cells but permits the passage of insulin and glucose. The technology simulates natural insulin secretion by the organism and decreases the risk of rejection of the implant as well.

The membrane is used in the implants because it controls the flow of insulin, glucose, and nutrients while effectively protecting the small islets from a potential attack by immunoglobulins or other contaminating agents.

An artificial pancreas incorporating the membrane was tested successfully on laboratory animals. Transposition on a human scale and the associated clinical tests are expected to take place.

\subsection{Oncology, liquid based monolayer cytology - paptest}

The conventional test, also known as smear test, consists of collecting samples of cells from the outer opening of the cervix using an Aylesbury spatula and an endocervical brush. The cells are placed on a glass slide and checked for abnormalities in the laboratory after staining using the Papanicolaou technique, in which dyes and acids are selectively retained by cells. The sample is then screened by a specially trained and qualified cytotechnologist using a light microscope.

Because the way the physician transfers the cells onto the glass slide is mostly critical, new technologies have been developed to create monolayers of cells on the glass slide using membrane technology. This monolayer is then transferred onto a microscope glass slide. This permits the histologist to perform a much more detailed analysis compared to the previous technology (smear test) of randomly transferring the cells to a microscope glass slide. Since multiple layers are often present, the diagnosis is less precise. The liquid sample has the advantage of being suitable for low and high risk HPV testing and reduced unsatisfactory specimens from $4.1 \%$ to $2.6 \%$.

\subsection{Micro controlled emulsions}

Emulsions are important commercial products in the food, cosmetic, and pharmaceutical industries. Emulsions consist of two or more immiscible phases, such as oil and water, or water and air, where a dispersed phase is suspended in a continuous phase, in the form of small droplets. Many of the most significant properties of emulsion-based products, such as shelf life, 
appearance, texture, flavour, encapsulation degree, and release rate are determined by the size of the droplets they contain. The size and the size distribution of droplets is the key to the stability of an emulsion, as it determines the rate of coalescence and its fitness for intended use.

Therefore and because of the high quality of pore size distribution and accurate control of pore shape, track etched membranes are used. They offer the possibility to choose the pore size, porosity and thickness. Moreover, they can be produced in roll stock, are sealable, are cheap compared to micro-sieves and are flexible. Also, the surface properties can be monitored as it is essential that the dispersed phase, which is often oil, does not wet the membrane.

3.6. Other fields of interest for track etched membranes

- in fuel cell where the membrane is used to replace classic Proton Exchange Membrane. Some recent observations have shown the advantages of use of track etched membranes such as no need to wet the membrane, larger proton conductivity, resistance to extreme conditions...

- in Lab-On-A-Chip : a network of porous cavities that can be used as a nanoreactor for a specific analysis whose reaction can be controlled by means of circuitry. A major application is the lab-on-a-chip technology.

- in OLED : an organic light-emitting diode (OLED), also light emitting polymer (LEP) and organic electro-luminescence (OEL), is any light-emitting diode (LED) whose emissive electroluminescent layer is composed of a film of organic compounds. The layer usually contains a polymer substance that allows suitable organic compounds to be deposited. They are deposited in rows and columns onto a flat carrier by a simple "printing" process. The resulting matrix of pixels can emit light of different colors. In this application, porous templates can be used for polymers confinement.

\section{Conclusions}

Track etched membrane have been firstly industrialized by GE in the 70ies using collimated charged particles in a nuclear reactor to create tracks further revealed by chemical etching. The membranes produced by this process shown important quality and technical limitations. In the mid 80ies, first improvements have been realized when particles accelerators have been used and a new company, Cyclopore, was created. Then, during the nineties, drastic improvements did follow coming from deep understanding of basics of interaction of particles, efficiency of 
chemical etching and eventual intermediate sensitization. This ends up to the basics of "second generation track etched membranes" manufactured and commercialized by it4ip.

The current applications are wide and some "first generation" customers already benefit from the new technology. Also, a completely new wide range of industries investigates the products described in this paper : the transport industry for integration in magnetic sensors and radars; telecommunications for systems of microwave absorption, while passing by screens for portable electronics; the energy sector in the development of fuel cells; as well as the health sector. Nevertheless, and because of confidentiality agreements in place, few of these new applications can be publicly related. 


\section{References}

[1] E. Ferain, R. Legras, Nuclear Instruments and Methods in Physics Research Section B, 208 (2003) 115

[2] M. Delvaux, S. Demoustier-Champagne, Biosensors and Bioelectronics, 18(7), (2003) 943

[3] L. Piraux, S. Dubois, S. Demoustier-Champagne, Nuclear Instruments and Methods in Physics Research Section B, 131(1-4), (1997) 357

[4] L. Dauginet-De Pra, E. Ferain, R. Legras, S. Demoustier-Champagne, Nuclear Instruments and Methods in Physics Research Section B, 196, (2002) 81

[5] H. Hanot, E. Ferain, R. Legras, Industrial applications of nano-track etched templates and film, Technical Proceedings of the 2006 NSTI Nanotechnology Conference and Trade Show, Volume 2 (2006) 806

[6] Price, P.B. and Walker, R.M., US Patent 3,303,085 (Feb. 7, 1967) 


\section{Figure Captions}

Fig. 1: Schematic of roll stock track etched membrane manufacturing.

Fig. 2: Intra and inter lot pore size distribution of high precision second generation nano track etched membranes ( $30 \mathrm{~nm} ; 50 \mathrm{~nm} ; 75 \mathrm{~nm}$ and $100 \mathrm{~nm}$ nominal pore size, pictures taken with SEM)

Fig. 3: Optical microscope picture of a patterned track eched membrane. Dark spot have pass trough straight pores and white area are not porous.

Fig. 4: Schematic of glucose monitoring principle involved in sensor. 
Figure 1

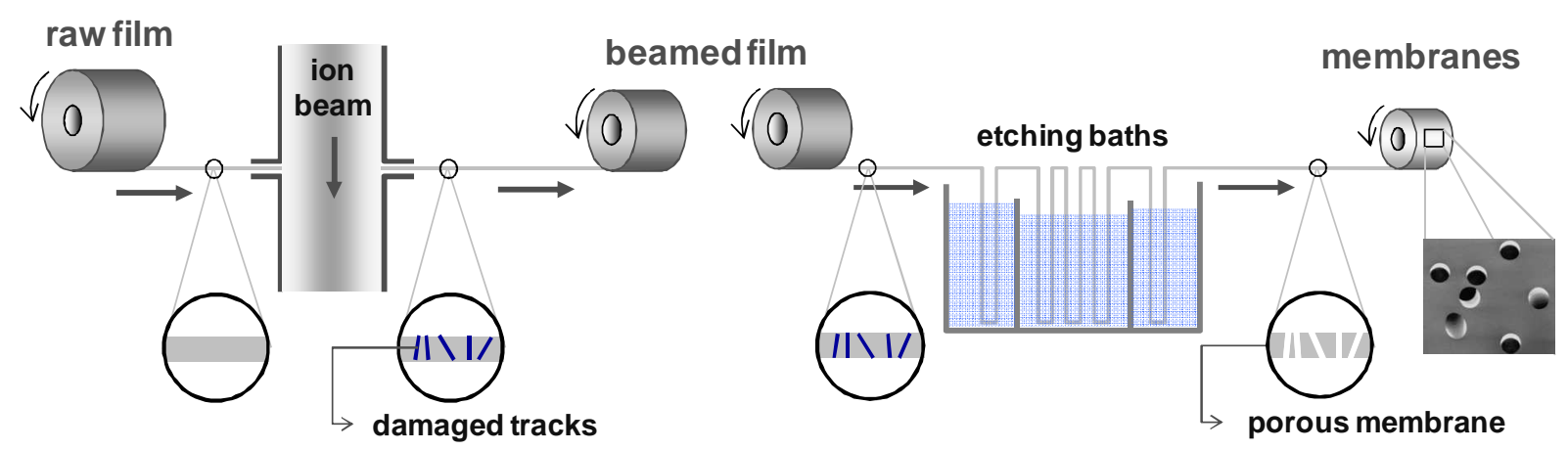

Figure 2

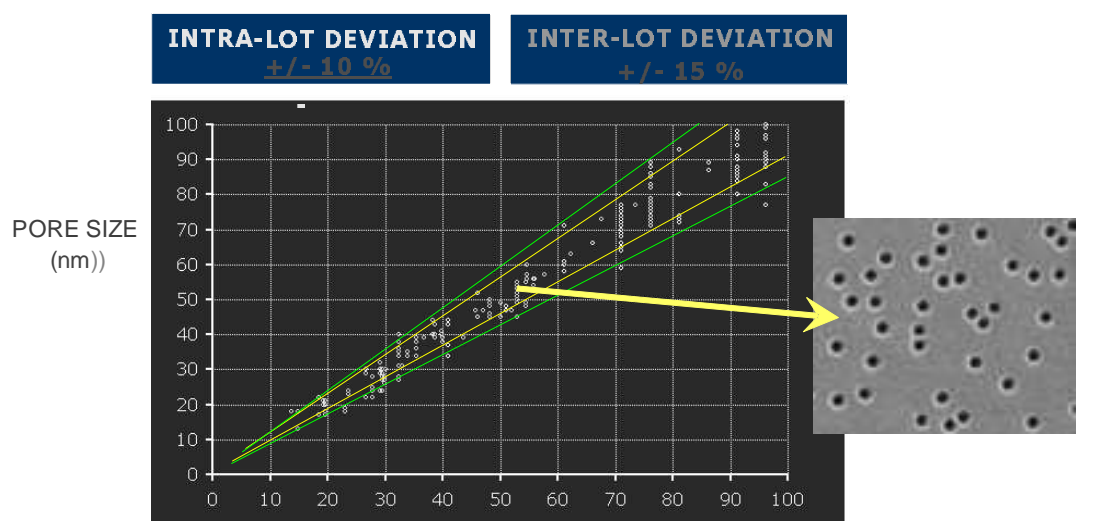

NOMINAL PORE SIZE (nm) 
Figure 3

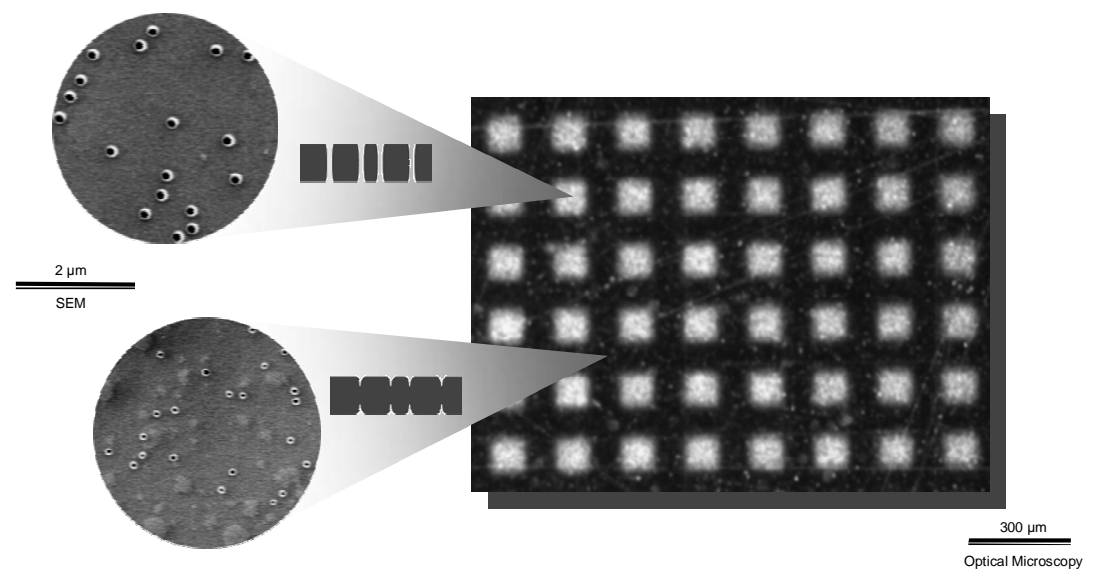

Figure 4

- GLUCOSE MONITORING

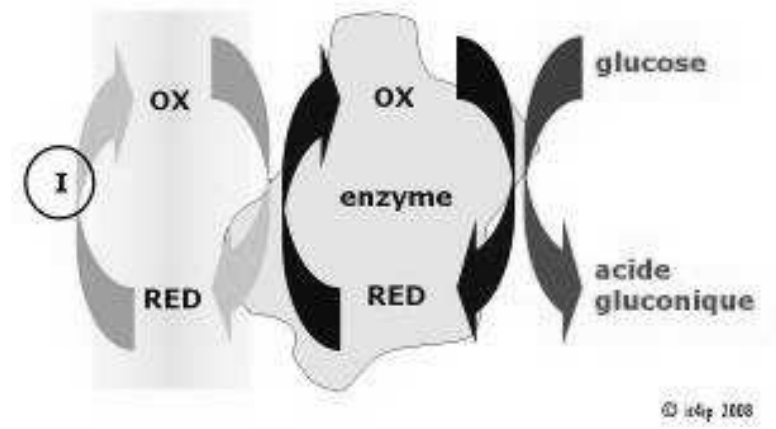

